Lingüística

Vol. 32-1, junio 2016: 115-119

ISSN 2079-312X en línea

ISSN 1132-0214 impresa

DOI: 10.5935/2079-312X.20160008

\title{
CLAUDIA PARODI
}

(1947-2015)

In memoriam

\author{
Micaela Carrera de la Red \\ Universidad de Valladolid - España
}

El 15 de noviembre de 2015 murió la Profesora Claudia Parodi, socia activa de la Asociación de Lingüística y Filología de la América Latina. La causa fue una enfermedad a la que ella siempre hizo frente con mucha valentía y todas las ganas de vencerla. Claudia Parodi murió en Los Ángeles, ciudad en la que vivía y en la que trabajaba como Profesora de Linguística Hispánica del Departamento de Español y Portugués de la Universidad de California (1991-2015).

En julio de 2013 el Director en aquellos momentos de ese mismo Departamento de Español y Portugués de la UCLA se dirigió a mí con la solicitud de una carta de presentación para que Claudia Parodi diera un paso más en su emérita carrera académica dentro de esa institución. Traigo aquí el párrafo con el que terminé aquella carta, porque contiene mi parecer sobre una persona tan recordada por mí: "Claudia Parodi es una persona muy generosa, al tiempo que una profesional de talla internacional. Es una profesora muy elocuente. Dota de gran sensibilidad todos los campos que investiga, lo lingüístico y lo literario, y lo hace en ambas lenguas, en inglés y en español. Claudia Parodi pone una gran dosis de emoción a la lingüística." Para entonces Claudia Parodi era una amiga más que una colega, una amistad imperceptible años atrás cuyo principio habría que buscarlo en la admiración que había producido en mí la lectura de trabajos suyos que hicieron de guía de mi formación como americanista, como el artículo sobre el "Orden de los pronombres átonos durante el primer cuarto del siglo XVI en el español novohispano", publicado en la Nueva Revista de Filología Hispánica $(1979,28.2,312-317)$ o el volumen Orígenes del español americano. Vol 1: Reconstrucción de la pronunciación, UNAM, 1995, que despertó mucho interés entre los estudiosos de la historia temprana del español de América.

Mexicana de nacimiento, de pensamiento y de sentimiento, cursó sus primeros estudios en la Universidad Iberoamericana a principios de los años setenta y los completó en la Universidad Nacional Autónoma de México, en la que inició sus tareas de investigación a mediados de los setenta como colaboradora en el estudio del habla de la ciudad de México junto al impulsor del proyecto de estudio de la norma culta en Hispanoamérica, el Profesor Juan M. López Blanch. Hasta mediados de los ochenta estuvo vinculada como investigadora y docente al Centro de Lingüística Hispánica, del Instituto de Investigaciones Filológicas de la UNAM (Ciudad de México). En su condición de tal, llevó a cabo la tarea de poner por escrito la recopilación de la bibliografía lingüística en México, primero en solitario y después en colaboración con otra gran lingüista mexicana y amiga de Claudia, Rebeca Barriga Villanueva. A fines de los ochenta Claudia Parodi era considerada en México una destacada investigadora de la lingüística latinoamericana y contaba con una amplia entrada en el Diccionario de escritores mexicanos, siglo XX (Ciudad de México: UNAM, 1988, 276-277), obra de Aurora Ocampo. 
Fue, sin ninguna duda, una investigadora inquieta y audaz e innovadora. Esa inquietud y esa audacia la llevó a adentrarse con éxito en numerosas áreas de trabajo: contribuyó al estudio y difusión de la literatura mexicana, colonial y actual, hizo aportaciones fundamentales en el ámbito de la lingüística histórica hispánica, contribuyó a la actualización de la lingüística actual hispánica con la aplicación del análisis generativista a puntos nucleares de la gramática del español, destacaron sus aportaciones como sociolingüista al contacto del español y el inglés en Los Ángeles así como sus contribuciones a la lingüística del contacto entre las lenguas amerindias y el español.

Coincidí con ella por vez primera en 1996, en el Congreso de la ALFAL que tuvo lugar en la Universidad de Las Palmas de Gran Canaria. Claudia Parodi se hizo responsable entonces del estudio de la historia del español en los Estados Unidos como parte de la llamada en aquellos momentos "Comisión del Proyecto Internacional Coordinado de Historia del Español de América, Canarias y Andalucía”, mientras a mí me encomendaron poco después dar comienzo a la historia del español en Colombia. Desde entonces, y en parte por esa tarea en común, fuimos encontrándonos en diversos foros, siempre con un trato muy amigable hacia mí como hacia todo el mundo que se le acercaba. Era una persona de trato fácil y afrontaba todas las situaciones, por difíciles que parecieran, con gran animosidad, en cada circunstancia con la palabra de aliento necesaria, sin "achicopalarse". Ese empuje lo tuvo Claudia Parodi hasta el último momento tanto en lo vital como en lo profesional.

Fue indudable su continua y sostenida excelencia en el ámbito académico, de hecho en 2012 recibió el Academic Senate's Distinguished Teaching Award otorgado por la UCLA debido a su relevante labor como docente en el ámbito de la enseñanza del español. Durante la ceremonia de entrega tuvo una emotiva intervención. Puso de relieve aquellos valores que, desde su punto de vista, comportaba la enseñanza de la Linguiística: según decía, la Lingüística contribuye a abrir las mentes a nuevos mundos y la lengua hay que estudiarla como expresión privilegiada de la cultura de una comunidad de habla. Preconizaba entonces, y ella misma lo ponía en práctica en cada uno de sus trabajos, la estrecha conexión existente entre lengua, cultura y educación.

Claudia vivía pendiente de sus alumnos, a muchos de los cuales orientaba de forma magistral hacia el mundo de la investigación. La calidad de Claudia Parodi como maestra queda patente en la notable cantidad de alumnos a los que ha dirigido sus trabajos de Tesis Doctoral y que hoy en día son ellos mismos profesores en diferentes universidades mexicanas y estadounidenses. Entre estos últimos existe la conciencia de que el comienzo de su carrera universitaria se sitúa en los seminarios a los que asistieron en el Centro de Estudios Coloniales Iberoamericanos (CECI), creado en la UCLA por la propia Claudia y dirigido por ella misma hasta su muerte y en el que se implicaban profesores y estudiantes de una amplia gama de disciplinas académicas (historiadores, literatos, filólogos clásicos, lingüistas). Este grupo de investigación organizaba un Seminario Permanente sobre temas relacionados principalmente con la literatura colonial mexicana, con especial atención a la figura de Sor Juana Inés de la Cruz, una figura que le apasionaba y sobre cuya personalidad y obra publicó títulos importantes. Una de las tareas realizada durante varios años por los integrantes del grupo que ella impulsara en UCLA fue la preparación de una nueva edición del Neptuno alegórico de Sor Juana Inés de la Cruz.

De su producción científica sobre puntos concretos de cultura, lengua y literatura histórica en el Virrienato de México destacan dos volúmenes de los que fue coeditora: en 2009, en colaboración con Karen Dakin y Mercedes Montes de Oca editó el volumen titulado Visiones del encuentro de dos mundos en América: lengua, cultura, traducción y transculturación (México: UNAM), y en 2011, junto a Jimena Rodríguez, publico el volumen Centro y periferia. Cultura, lengua y literatura virreinales en América (Madrid/Frankfurt: Iberoamericana/Vervuert). 
Este último volumen es el fruto de la colaboración de especialistas en literatura, lengua e historia cultural con el objetivo de reconstruir, analizar y teorizar sobre los efectos que la presencia de España y Portugal en América Latina tuvo en las lenguas, literaturas y realidad cultural de las lenguas amerindias y en el español. La propia Claudia se inició desde época bien temprana en el análisis de documentación histórica para explicar cuestiones de interés sobre los orígenes y la etapa colonial mexicana. Su interés por la filología más auténtica permitió redescubrir un buen número de textos coloniales latinoamericanos, en particular crónicas de los siglos XVI y XVII y narraciones de viajes. Se puede reseñar, entre otros muchos trabajos, un artículo del año 1992 titulado "El habla de un 'caballero de la tierra' novohispano del siglo XVI" (Nueva Revista de Filología Hispánica, XI/1, 29-43); la lectura de este trabajo es decisiva para comprender la actitud hacia la sociedad criolla en Nueva España desde 1521 a 1610.

La consideración conjunta de diferentes planos (histórico, literario, cultural y lingüístico) en la investigación era fruto de la concepción de Claudia Parodi sobre la lengua como manifestación esencial de la cultura y, a su vez, de esta como expresión relevante de la sociedad. Desde esa manera de trabajar, Claudia Parodi hizo aportaciones de un enorme interés sobre la situación linguística en la época barroca mexicana a través de la literatura. Defendió con ahínco la fuerte impronta neolatina en la conformación de la intelectualidad novohispana y le concedió tal importancia en la "hispanización" de aquella sociedad colonial mexicana, que hablaba incluso de la existencia de una situación de "diglosia" latín/castellano en las capas más cultas e influyentes de la sociedad. Para comprender correctamente la aplicación del concepto de Ferguson (1959) a la sociedad barroca novohispana es necesario conocer como ella conocía el contexto histórico concreto al que se refería: con una erudición y nivel de conocimientos muy elevados.

Practicaba lo que se llama "sociofilología" al poner el énfasis en el contexto de los textos, tal como se puede ver en trabajos suyos como "Diglosia creole indianization and theater: the tocotines and Mexican songs", publicado en Dramatic and theatrical performance at the time of the Habsburgs (Madrid/Frankfurt, Iberoamericana/Veruert, 2009: 251-269), o "Contact languages before the time of Sor Juana: its effects on a literature", publicado en Feathers, brushes, chords. Studies and Spanish and Latin American literature (XVI-XVIII centuries) culture (Mexico, Metropolitan Autonomous University, 2011: 403-416), o también sobre la lengua de los arcos de triunfo "The language of the festivals: Triumphs and carols", publicado en Theatre and power in the time of Charles II, Celebrations around kings and viceroys (Madrid, Universidad de Navarra, 2007: 221-236).

La diglosia latín/castellano formaba parte constitutiva del proceso de "hispanización" que experimentó el continente americano en general y el área mexicana en particular durante el período virreinal. Pero Claudia Parodi consideraba imprescindible el manejo de otro concepto para comprender en toda su dimensión la historia del español en América: esta era la noción de "indianización", la otra cara de la moneda, sin la cual resultaría incomprensible todo análisis de la historia lingüística americana, tal como ella misma fue exponiendo en distintos foros $y$ publicaciones, como por ejemplo en el trabajo titulado "El español y su cultura en el nuevo mundo: la indianización", publicado en la Revista Internacional de Lingüística Iberoamericana, 10, 2 (2012): 149-160.

Claudia Parodi ha hecho magníficas contribuciones al estudio de los contactos entre el español que llegó a América y las lenguas amerindias de los pueblos indígenas, de forma particularmente difícil e interesante en épocas de orígenes, desde las primeras décadas del siglo XVI. 
Intercambiamos ideas sobre el modo de trabajar en la historia de la lengua española en América desde la "semántica cultural", una metodología de trabajo en la que funcionan ambas nociones, 'hispanización' e 'indianización', y en la que se parte de que los signos lingüísticos -en el preciso momento del encuentro de hablantes con una configuración del conocimiento radicalmente distinta y, por lo tanto, con categorías cognitivas diferentes- se convierten en signos biculturales, es decir que el mismo significante sirve para significados totalmente distintos.

Claudia expuso estas teorías en distintos foros y en diferentes publicaciones, entre las que merece destacarse el titulado "La semántica cultural y la indianización en América", que presentó en las Actas del XV Congreso de la Asociación Internacional de Hispanistas (México, Fondo de Cultura Económica, 2007: 211-222), o el titulado "Bifurcación del español en dos continentes: contacto entre indígenas y españoles. "Indianización" e "hispanización" en la Nueva España y sus confines, publicado en las Actas del IX Congreso Internacional de Historia de la Lengua Española (Cádiz, 2012) (Madrid/Frankfurt, Iberoamericana/Vervuert, t. II, 2015: 1999-2012). En otros trabajos, la semántica cultural histórica se complementa con un planteamiento de índole sociolinguística, como la explicación que Claudia daba a la formación de la variedad "vernácula" del español en América en un trabajo publicado en 2001 en la revista Journal of the Sociology of Language con el título "Contacto de dialectos y lenguas en el Nuevo Mundo: la vernaculización del español en América” (149: 33-53).

Consciente de la realidad cotidiana que vivía la comunidad latina en la ciudad de Los Ángeles, los esfuerzos académicos de Claudia Parodi incluyeron una iniciativa clara de búsqueda desde la sociolingüísitica de estudios que dieran respuesta a las necesidades de convivencia en una sociedad bilingüe y bicultural. Por eso su inquietud le condujo a crear en su universidad un nuevo Centro de Estudios del Español en los Estados Unidos (CEEEUS), que comenzó a funcionar en el 2010, una iniciativa conducente a fomentar la investigación sociolinguística del contacto inglés/español en Los Ángeles (Estados Unidos). Testimonio de ese compromiso de Claudia Parodi con el entorno en el que se desenvolvía su tarea académica e investigadora es la presencia en su curriculum de trabajos de investigación sobre el contacto inglés/español desde la primera mitad de la década de los noventa, poco después de su traslado desde México a esa nueva realidad social y vital de la sociedad californiana: "Bilingüismo y préstamo léxico: español chicano vs. español mexicano" (Mester, 23, 1994: 1-15). Esta línea de trabajo será una constante en la trayectoria de Claudia Parodi: "Contacto de dialectos en el español de Los Angeles", publicado en Ensayos de lengua y pedagogía (California, Universidad de California. Linguistic Minority Research Institute, 2003: 23-38), o "Multilingüismo y diglosia: Los Angeles", publicado en El español en América: Diatopía, diacronía e historiografía (México, UNAM, 2006: 433-456).

Otra faceta digna de destacar en la personalidad de Claudia Parodi, acorde con su carácter eficiente y colaborador, es la de la organización de eventos científicos. En 1996 fue coeditora con Carlos Quícoli, Marco Saltarelli y María Luisa Zubizarreta del volumenAspects of Romance Linguistics. Proceedings of the 24th Linguistic Symposium on Romance Languages, un libro muy interesante sobre distintos tópicos de la sintaxis generativa aplicada a las lenguas romances.

Durante los últimos siete años he tenido el honor de trabajar con Claudia en la organización de cuatro encuentros científicos como actividad destacada del "Proyecto de Historia del Español de América", auspiciado por la ALFAL. Fue una gran casualidad que Claudia Parodi y yo misma nos dirigiéramos a la dirección de la ALFAL, en aquellos momentos en manos de la Profesora Alba Valencia, con la misma petición: la pertinencia, dentro de la Asociación, de un espacio, en aquellos momentos inexistente, en el que pudieran reunirs e intercambiar sus trabajos investigadores con interés en cualquiera de los numerosos aspectos de la parte histórica del español en el continente americano desde las múltiples perspectivas posibles en la actualidad. 
La primera ocasión para la puesta en marcha de ese Proyecto llegó en agosto del 2008 en Montevideo (Uruguay), en el contexto del XV Congreso de la ALFAL, con la aquiescencia de su comité organizador. Claudia y yo misma estábamos de acuerdo en que el propósito central del Proyecto sería servir de marco abierto para exponer y discutir ideas y propuestas de análisis que en la medida de lo posible se difundieran en forma de publicación impresa o electrónica. La convocatoria se vio recompensada con la participación en aquella ocasión de especialistas de la talla de María Luisa Rivero (Profesora Emérita de la Universidad de Ottawa), Rafael Cano Aguilar (Catedrático de la Universidad de Sevilla) o Enrique Obediente Sosa (Profesor Emérito de la Universidad de Los Andes, Mérida, Venezuela). Al Congreso inicial para el Proyecto en Montevideo siguió una segunda Jornada Científica, o en terminología de la ALFAL, un "ALFALito", organizado bajo el amplio rótulo de "Historia del Español en América. Nuevas aproximaciones y perspectivas de estudio: Contactos, Sintaxis y Tipos de Textos". Esa Primera Jornada del Proyecto para el Estudio Histórico del Español de América se celebró en septiembre del 2009 en la Facultad de Filosofía y Letras de la Universidad de Valladolid (España). Volvimos a organizar las sesiones del Proyecto de la Historia del Español de América en el XVI Congreso Internacional de la ALFAL, celebrado en junio del 2010 en la Universidad de Alcalá de Henares (España), y en el XVII Congreso Internacional de la ALFAL, celebrado en julio del 2014. Y de nuevo, en marzo de 2013 organizamos nuestra segunda Jornada del Proyecto Histórico del Español de América, esta vez en la Ciudad de México.

Con las participaciones en estas reuniones y congresos alcanzamos otro de los propósitos de este Proyecto: contar con estudios pioneros de documentos lingüísticos de diferentes áreas geográficas pertenecientes a diferentes momentos y niveles del ámbito hispanohablante: se presentaron avances sobre el español de California en el siglo XIX (Covadonga Lamar) o sobre el español y su contacto con el galés en los orígenes de la provincia del Chubut en la Patagonia argentina (Profesora Ana Virkel, Claudia Iun).

En todas las reuniones se lograba un ambiente, por un lado, de cordialidad y mucha confianza y, por otro, de un alto nivel científico. Tal como era la propia Claudia, amable e inteligente. A Claudia Parodi le alcanzó el final de la enfermedad mientras preparábamos un nuevo congreso sobre Contactos e Historia del Español en América, en el Cuzco (Perú) para este julio del 2016. Estará presente Claudia en el recuerdo de todos los que la tratamos y será celebrado en su honor, la mejor manera de rendirle homenaje. 